\title{
On Badminton Layered Teaching in Colleges and Universities
}

\author{
Pengyi Yan \\ Xi`an International University, Xi`an Shaanxi, 710077, China
}

Keywords: colleges and universities; badminton; layered teaching

\begin{abstract}
In view of the continuous deepening of the reform of higher education, more and more attention has been paid to the teaching of physical education in colleges and universities in China. The research on the teaching of physical education in colleges and universities has also developed rapidly. Badminton is one of the important items in college sports teaching and is deeply loved by college students. In order to improve the level of badminton education and teaching, the introduction of advanced teaching methods is extremely important, and layered teaching is such a scientific teaching method. In view of this, the use of layered teaching method has a good role in promoting the quality of badminton teaching in colleges and universities. This paper analyzes the meaning and principles of layered teaching, expounds the necessity of implementing the teaching of badminton level in colleges and universities, and puts forward some countermeasures to carry out the teaching of badminton level in colleges and universities.
\end{abstract}

\section{Introduction}

University sports is the last stage in the school sports system, and it is also an important part of whether college students can form a concept of lifelong sports. Because of the continuous deepening of the reform of Chinese college badminton teaching, the introduction of more scientific teaching methods has become a very important content. The teaching practice in recent years has confirmed that if we only use the old teaching methods and ignore the differences among the individual students, the level of students with relatively high skills will not be further improved, and those students with poor skills will not be able to improve. Can not keep up with the rhythm of teaching. Therefore, college badminton curriculum teaching should be implemented according to the different types and levels of students, so that students can maximize their learning effectiveness on the basis of their current level, and lay a good foundation for practicing the concept of lifelong sports.

\section{The Meaning and Principle of Layered Teaching}

\subsection{The Meaning of Layered Teaching}

Layered teaching mainly refers to the fact that learners are divided into different levels according to the actual conditions of learning skills, ideological abilities, etc., and teach different contents, so that learners can receive teaching methods that are most suitable for their own reality. Continuously enhance the pertinence of the teaching process, so as to provide learners with a better learning situation, effectively enhance their enthusiasm for learning, and then improve the actual effectiveness of teaching.

\subsection{The Principle of Layered Teaching}

In implementing the hierarchical teaching method, in order to ensure the scientific and practical teaching, we must follow the corresponding principles. The main four principles are as follows:

The first is to implement the principle of subjectivity. Although the stratification implemented by the students is performed by the teachers, it is still the students who have the main status. Therefore, the important value of the main position of the students must be clearly stated in the teaching process. Teachers should place themselves on equal footing with students and strengthen communication and 
exchange between the two parties. It is necessary to consider empathy, consider it from the perspective of students, choose the most reasonable form and content of teaching, and continuously improve the students' enthusiasm for learning.

The second is to implement the principle of concealment. Stratification teaching should be based on relevant standards to classify students into different levels, but the stratification basis is not suitable for directly informing students so as not to have a bad influence on their self-confidence and self-esteem, and it is also not conducive to better promoting teaching. The development of work. Therefore, the layered teaching must be hidden. It is difficult for students to deduce the stratification basis from the stratification and ensure that they maintain their conscience.

The third is to implement the principle of progressiveness. Different levels of learners in stratified teaching need to establish their own goals. They should not only pay attention to the current situation of students and set goals in the short term, but also should take into account future learning prospects and determine long-term development goals. Actively guide students to carry out their studies from shallow to deep, not only to improve their learning ability.

The fourth is to implement the principle of development. Because the learning process of learners continues to change, teachers should grasp the students' learning situation from a development perspective in hierarchical teaching and make corresponding adjustments to student groups based on the actual effects of learning so as to actively encourage students to be courageous. Pursue higher goals.

\section{The Necessity of Implementing Badminton Layered Teaching in Colleges and Universities}

\subsection{Enhance the pertinence of layered teaching}

College students in the high school period because of their own economic conditions, site allocation, practice time and other factors, so there is a considerable difference in the level of badminton. Introduce layered teaching method in college badminton classroom teaching, pay attention to teaching students in accordance with their aptitude, develop different teaching objectives for different levels of students, and implement different training methods, which will help students complete the teaching tasks arranged by teachers independently and inspire them. The pride of success meets its need for self-esteem.

\subsection{Break through the constraints of traditional teaching methods}

Badminton teaching in the traditional sense seems to be closed and dull, mainly reflected in two points: First, the teaching material and teacher are the core, and the content of the teaching is the basic content. It ignores the students' subjective status. The second is to focus solely on improving students' physique while ignoring diversified teaching methods. After introducing layered teaching, it will be able to better break through the constraints of traditional teaching, achieve a people-centered approach, emphasize the suitability of people, and create learning methods suitable for learners so that learners at all levels can taste The taste of success, but also improved the relationship between teachers and students, enhance the effectiveness of teacher-student exchanges. When preparing for classes, badminton teachers are guided by well-prepared students according to their respective problems at different levels, which greatly expands the teaching capacity, improves the quality of classroom teaching, and is highly compatible with the physical and mental health of college students. Development Law.

\subsection{Enhance lifelong sports awareness}

To nurture lifelong sports concepts of college students, we must not only stimulate their enthusiasm for learning, but also focus on the diversification of teaching methods. Traditional Chinese badminton teaching methods in colleges and universities are quite numerous, covering example teaching, problem teaching, and inquiry teaching. However, due to the advancement of higher physical education teaching reform, the physical education teaching in Chinese universities is 
also continuously improving. It is very much in line with the personalized development needs of the group of college students, allowing them to select sports activities that meet their own characteristics based on their interests, activities, and adaptability. In the implementation of teaching, teachers should allow students to fully express their opinions, focusing on improving students' ability to think independently and actively solve problems. Therefore, stratified teaching is also an important way to inspire college students to better participate in badminton sports. It can promote college students to switch from passive learning to active training and lay a good foundation for establishing lifelong sports awareness.

\section{Some Countermeasures to Develop Badminton Layered Teaching in Colleges and Universities}

\subsection{Elaborate arrangements for badminton teaching}

A good teaching environment has very important value in badminton teaching. Undergraduate students can adjust their training intensity and goals based on their actual learning of badminton in order to maximize their physical reserves and learning ability. Therefore, badminton teachers should fully grasp the relevant issues that should be paid attention to in the process of classroom design and make meticulous arrangements for the content of the teaching. For example, teachers should carefully explain the guiding ideology of physical education. In the past, physical education classes were often regarded as optional courses. After introducing layered teaching, students should be guided to expand their perspective in badminton teaching and improve their physical fitness. Specialized badminton teachers should make full use of the opportunity for pre-class warm-up to let students understand the curriculum. Sports games should be introduced during the warm-up process so that college students can have greater interest in participating in sports. However, it is necessary to control the time for the pre-school warm-up stage of the game teaching. It must not be excessive to avoid the undergraduates being too obsessed with it. In this way, other students' interest in badminton can be triggered, their cognitive ability can be improved, and the effectiveness of badminton classroom teaching can be fundamentally improved.

\subsection{To conduct layered teaching according to the actual situation of students}

The focus of the college level teaching of badminton is how to stratify the students. In reality, the level of badminton skills of undergraduate students is very different. Some college students began to engage in badminton sports in the primary and secondary schools and may even have special training. At the same time, there are still some other students who have barely been in contact with badminton, so that it is difficult to keep up with the teaching pace of teachers in the classroom. When faced with some difficult training programs, it is easy to be discouraged so that the technical level of one's own badminton can not be greatly improved. Faced with this universal problem, badminton special teachers should first conduct a training competition for all students in order to grasp the students' basic level of badminton, and then implement the corresponding stratification according to different levels. In the next step, teachers should carry out targeted training according to the specific conditions of different groups of students and actively encourage students at the same level to conduct more interactive interactions. For example, the teacher may allow members of the training team to conduct internal cycling competitions, use the competition activities to implement the internal communication and display of the group, and better play the enthusiasm of the college students, thereby creating a better training space for college students. . At the same time, because the difference in the basics of badminton learning among college students is different, there is a big difference in the mastery of badminton technology. Specialized badminton teachers should allow students of different levels to get the maximum improvement in their respective starting points. Therefore, targeted courses should be set up so that undergraduates can reduce objective differences as much as possible so as to improve the overall quality. aims. For example, badminton courses in some colleges and universities require teachers to provide students with a certain degree of technical ability and to comment on the 
performance of their training. Teachers can set different learning goals for the undergraduates according to their actual conditions, so that students can continue to break through their own limits in targeted learning, and then achieve greater breakthroughs in badminton technology and experience the joy of success. .

\subsection{Fully understand students' badminton skills}

For college badminton special teachers to improve the students' level of badminton, they should more fully grasp the students' detailed training ability. A considerable number of students do not have an accurate and comprehensive understanding of the training tasks assigned by the teachers, so that the knowledge obtained in badminton training is relatively small, which results in the inability of teachers to ensure the quality of badminton teaching. In view of this, in order to further improve college students' badminton skills, teachers should regularly or irregularly test college students' badminton technical skills so that they can easily adjust the focus and direction of their next training in a targeted manner. The process becomes more comprehensive. Teachers should use more humane methods to master the actual abilities of undergraduates when they are at the bottom, but they should also pay attention to mastering the standards. For example, too many games will make college students ignore the main task of badminton learning. Therefore, in the teaching of badminton in universities and colleges, it is necessary to use appropriate criteria so that the students' bad balance in badminton learning does not show a large shift, in order to improve their overall physical fitness. Complex colleges and universities can maintain a good attitude from beginning to end, and effectively promote the improvement of learning ability in other subjects.

\subsection{Implement comprehensive evaluation of badminton skills}

Comprehensive assessment is the last important link in the teaching of badminton courses, and it is also the main measure index of teaching effectiveness of special badminton teachers. Therefore, badminton teachers should set a reasonable and scientific evaluation method as much as possible, and must not use the curing standard to examine college students' badminton skills. This is because each university student has a different starting point for learning, and there are also differences in the extent of his progress. The rationality of comprehensive assessment methods will directly affect the subjective initiative of their badminton learning in the future. Therefore, teachers should set a comprehensive assessment index that can truly reflect the progress of college students in badminton, so that the students can truly understand their own badminton technical ability, so that they can encourage a more positive attitude. Put into later badminton teaching. For example, badminton special teachers can conduct comprehensive physical fitness tests before comprehensive assessment, so that college students can master their own physical fitness data. In this way, in the subsequent formal evaluation, it will be able to better adjust its own mentality so as not to produce negative emotions. At the same time, in the face of different levels of college students, the content of comprehensive assessment should also be different. For undergraduates with general technical ability of badminton, the content of comprehensive assessment should focus on physical fitness testing. For college students with excellent badminton skills, the content of comprehensive assessment should be focused on the evaluation of their badminton technical ability. From this, we can grasp the progress of badminton skills of all students and facilitate the teachers' teaching tasks in the next step.

\section{Summary}

In general, because of the individual differences among college students themselves, they will have different learning outcomes in the learning process, and they cannot guarantee a good teaching schedule. As a result, some students are wasting precious time and even Badminton study loses interest. Therefore, in the teaching process of college badminton courses, actively promoting the use of hierarchical teaching methods can effectively solve the problems existing in traditional badminton teaching, so that college students can get a true sense of teaching according to their abilities and devote themselves fully to the study of badminton courses. Through training, the quality of college 
badminton classroom teaching is improved, and the popularization of badminton sports in colleges and universities is promoted.

\section{References}

[1] Chai Zhongxue, Fu Xiaogang. An Experimental Study on the Stratified Teaching Mode of Badminton Special Course in Changzhi College, Journal of Changzhi University, 2016(2).

[2] Zhou Dechao, Xuan Tao. Study on the Level Teaching Reform of University Badminton Course, Journal of Kaifeng Institute of Education, 2016(5).

[3] Wang Lei. An Experimental Study of Teaching by Levels in Badminton Teaching in Colleges and Universities, Asia-Pacific Education, 2016(12).

[4] Feng Qibin. An Experimental Study on the Stratified Teaching Model in the Teaching of College Badminton Specialized Courses, Journal of Lanzhou University of Arts and Science (Natural Science Edition), 2018(3). 